\title{
Precificação da Água e Eficiência Técnica em Perímetros Irrigados: Uma Aplicação da Função Insumo Distância Paramétrica
}

\author{
Moisés de Andrade Resende Filho* \\ Alexandre Stamford da Silva ${ }^{\star \star \star}$
}

\author{
Felipe Augusto de Araújo**

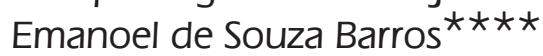

\begin{abstract}
Resumo
A maior pressão sobre os recursos hídricos tem estimulado a busca por mecanismos para induzir o uso eficiente da água. Precificar corretamente a água constitui uma etapa necessária à implementação desses mecanismos. O artigo aplica programação linear para estimar a função logaritmo insumo distância translog de modo a detectar ineficiências técnicas dos produtores e estimar a disposição a pagar pela água e elasticidades próprios-preços e preços-cruzados dos fatores de produção. Utilizam-se dados quanto ao valor da produção, área irrigada, gasto com insumos diversos, mão de obra, capital e volume de água para 41 colonos de perímetros irrigados do Submédio São Francisco em Petrolina, PE e Juazeiro, BA. Os resultados indicam que políticas públicas podem induzir a conservação da água via provimento de assistência técnica, visando maior eficiência técnica dos produtores e cobrança crível pelo uso da água.
\end{abstract}

\section{Palavras-Chave}

disposição a pagar pela água, elasticidades-preço, eficiência técnica, função insumo distância, programação linear

\begin{abstract}
Increased pressure on water resources has stimulated the search for mechanisms to induce efficient water use. Getting prices right is an important necessary step toward implementing such mechanisms. This article applies linear programming to estimate the translog logarithm input-distance function, estimate the willingness to pay for water, own and cross-price input elasticities, and detect technical inefficiencies of producers. In so doing, we use data on total production value, irrigated land, labor, capital, water use, and 'other inputs' obtained from 41 producers of public irrigation projects in Sub medium São Francisco River, Brazil. Results indicate that public policies can induce water conservation by credibly charging for water use and providing technical assistance to increase producers' technical efficiency.
\end{abstract}

\section{Keywords}

willingness to pay for water, price-elasticities, technical efficiency, input-distance function, linear programming

\section{JEL Classification}

Q25, Q12, D24

\footnotetext{
+ Os autores agradecem ao professor Rodney B.W. Smith, aos participantes do seminário de pós-graduação do Departamento de Economia da UnB e a um parecerista anônimo pelas inestimáveis sugestões e críticas, ressaltando que eventuais erros remanescentes são de nossa inteira responsabilidade. Essa pesquisa foi financiada com recursos do edital MCT/CNPq 61/2005.

* Professor Adjunto, Departamento de Economia, Universidade de Brasília (UnB). E-mail: moisesresende@unb.br.

** Mestrando em Economia, Universidade Federal de Minas Gerais (CEDEPLAR - UFMG). E-mail: faraujo@cedepar.ufmg.br.

$\star \star \star$ Professor Adjunto, Departamento de Economia, Universidade Federal de Pernambuco (UFPE). Email: alexandre@stamford.pro.br.

$\star \star \star \star$ Professor Adjunto, Universidade Federal de Pernambuco (UFPE). Email: leonamebr@hotmail.com.

Endereço para contato: Universidade de Brasília - Departamento de Economia - Campus Universitário Darcy Ribeiro ICC - Norte - Brasilia - DF. CEP: 70919-970.

(Recebido em junho de 2009. Aceito para publicação em fevereiro de 2010).
} 


\section{Introdução}

A quantidade de recursos hídricos renováveis disponíveis na Terra é finita e estimada em $47.000 \mathrm{~km}^{3}$ /ano, dos quais $41.000 \mathrm{~km}^{3}$ são economicamente exploráveis (JOHANSSON, 2000). Considerando-se que a quantidade de água bruta disponível por país é praticamente constante no longo prazo e em um cenário de crescimento da população mundial, Johansson et al. (2002) estimam que a disponibilidade de água, em 2050, será da ordem de $4.380 \mathrm{~m}^{3}$ por pessoa/ano, o que não é desprezível. Note-se que a Organização Mundial da Saúde (OMS) classifica as regiões com base em sua capacidade de fornecer água em: muito rica, se é capaz de fornecer mais do que $10 \mathrm{mil} \mathrm{m}$ /habitante/ano; rica, se é capaz de fornecer mais de $5 \mathrm{mil} \mathrm{m} /$ habitante/ano; pobre, se é capaz de fornecer menos do que $2,5 \mathrm{mil} \mathrm{m}$ 3/habitante/ano, e em situação crítica se não é capaz de fornecer mais do que $1,5 \mathrm{mil} \mathrm{m}^{3} /$ habitante/ano.

Embora $4.380 \mathrm{~m}^{3}$ de água por pessoa/ano, em 2050, não sugira a escassez de água até lá, sabe-se que a distribuição geográfica dos recursos hídricos é desigual. No Brasil, um país privilegiado com cerca de $12 \%$ de toda a água doce do mundo, cerca de $72 \%$ desses $12 \%$ estão situados na região norte do País, onde vivem $7 \%$ da população brasileira, e apenas 3\% desses 12\% estão localizados no Nordeste brasileiro, onde vivem $28 \%$ da população. Ademais, dentro da região Nordeste, a distribuição geográfica dos recursos hídricos é muito desigual. Por exemplo, com ofertas hídricas de cerca de 1.440 e $1.320 \mathrm{~m}^{3}$ por habitante/ano, os Estados da Paraíba e Pernambuco estão em situação crítica. Já os Estados do Maranhão e Piauí, com ofertas hídricas de 17.200 e $9.600 \mathrm{~m}^{3}$ por habitante/ano, são classificados como ricos em termos de suas capacidades de fornecer água (SUASSUNA, 2008).

A potencial escassez de recursos hídricos gera a necessidade de se estudar mecanismos que induzam alocações eficientes dos recursos existentes. Nesse tocante, a cobrança pelo uso da água pode ser um importante indutor de eficiência na alocação da água, encorajando, inclusive, a sua conservação. Dentro dessa ótica, o Banco Mundial instituiu, em 1993, com a resolução Water Resource Policy, que empréstimos para o financiamento de projetos de investimento envolvendo recursos hídricos incluíssem obrigatoriamente um componente exigindo a implementação de algum tipo de esquema de precificação/cobrança pelo uso da água (JOHANSSON, 2000).

Estima-se que a agricultura irrigada consuma algo entre $75 \%$ e 90\% de toda a água consumida em países em desenvolvimento e contribua com 38\% da produção de alimentos no mundo (WORLD BANK, 2001). Note-se aqui a diferença entre os conceitos de utilização e consumo de água. O conceito de utilização contabiliza a quantidade efetivamente utilizada de água em uma dada atividade. Já o conceito de 
consumo leva em conta a quantidade efetivamente consumida, ou seja, a diferença entre a quantidade utilizada e reaproveitada de água. A agricultura irrigada é uma das atividades que mais consomem água no mundo, porque a quantidade reaproveitada de água após a irrigação é praticamente nula.

O total da área para agricultura irrigada no mundo cresceu a taxas de aproximadamente 2,4\% ao ano na década de 1970 e 14\% ao ano nas décadas de 1980 e 1990, com taxa projetada de $1 \%$ ao ano para os próximos 34 anos (FAO, 2003). Assim, a agricultura irrigada deve continuar sendo uma grande consumidora de recursos hídricos, principalmente em um cenário de crescimento populacional e aumento da renda per capita mundial, com consequente aumento da pressão sobre a produção de alimentos.

Em termos teóricos, a cobrança pelo uso da água pode racionalizar o seu uso, aumentar a sua produtividade e eficiência, redistribuir custos sociais, disciplinar a localização dos usuários, promover o desenvolvimento regional integrado em suas dimensões social e ambiental, além de servir na melhoria da qualidade dos efluentes lançados nos mananciais. Contudo, não faltam exemplos de experiências internacionais malsucedidas na aplicação de instrumentos econômicos como a cobrança pelo uso da água. Kraemer et al. (2003) apresentam exemplos de utilização de instrumentos econômicos no gerenciamento da água no México, Colômbia, Jamaica e Brasil, e argumentam que os mesmos não atingiram os objetivos preconizados devido à inadequada imposição de regras e à insuficiente cobertura de usuários. Seroa da Motta et al. (2003) relatam que a cobrança pelo uso da água, desde março de 2003 na Bacia do Rio Paraíba do Sul, um rio federal, aparentemente não tem alterado o padrão de uso da água. Por tudo isso, os resultados obtidos no presente estudo devem ser analisados sob a perspectiva de que o efeito racionalizador da cobrança pelo uso da água é preconizado pela teoria e, portanto, potencial.

O presente artigo apresenta uma aplicação do método de estimação via programação linear de uma função insumo distância paramétrica para a obtenção dos preços sombra ou disposição a pagar pela água. Uma vez extraída essa informação privada do produtor, pode-se, em tese, utilizá-la na precificação e cobrança pelo uso da água em projetos de irrigação.

Os poucos estudos econômicos disponíveis no Brasil sobre precificação da água para a agricultura irrigada se limitam em determinar a tarifa que permite cobrir os custos de operação e manutenção de sistemas de suprimento de água destinada à irrigação (LANNA, 1995). Outros estudos tratam da estimação do preço eficiente ou preço ótimo, capaz de refletir a escassez da água, como atestam Albino (2003) e Carrera Fernandez (2000), ao revisarem a literatura sobre o assunto. Entretanto, 
a estimação da disposição a pagar pela água, via aplicação do método de estimação de uma função insumo distância paramétrica, não foi ainda empregada por estudos acerca da precificação da água no Brasil. Nesse intuito, o presente artigo contribui com a literatura, ao aplicar, pela primeira vez, tal método na precificação e análise de eficiência técnica do uso da água na agricultura com dados brasileiros. Note-se que esse método foi anteriormente empregado por Kumar (2006) em um estudo sobre a racionalização do uso da água pela indústria na Índia.

O presente artigo adota o seguinte esquema: inicialmente, enumera e discute os principais métodos utilizados na cobrança pelo uso da água e os métodos utilizados na precificação da água. Em seguida, apresenta o modelo conceitual, o método de estimação de uma função insumo distância paramétrica, descreve os perímetros irrigados amostrados e os dados utilizados. Finalmente, o artigo apresenta e analisa as estimativas da função logaritmo insumo distância e os preços sombra dos fatores de produção, inclusive da água, e analisa a eficiência técnica dos colonos e as elasticidades-preço da demanda por fatores com foco sobre políticas públicas que poderiam ser desenhadas de modo a induzir a racionalização do uso da água.

\section{Cobrança pelo Uso da Água}

Johansson (2000) enumera três métodos de cobrança pelo uso da água em projetos de irrigação: o método volumétrico, não volumétrico e o de mercado. $\mathrm{O}$ método volumétrico presume a cobrança por volume de água consumida e requer, portanto, o conhecimento do volume consumido de água por usuário. O estabelecimento do preço e monitoramento do uso da água, bem como a cobrança ficam a cargo da autoridade central ou de uma associação de usuários. Os custos de implementação do método volumétrico são elevados, pois exige, em geral, a instalação de medidores de consumo, a realização de manutenções de rotina e mensurações periódicas. No entanto, quando o fluxo de água é razoavelmente constante, a cobrança pode ser feita com base no tempo de fornecimento de água (e.g., $\mathrm{R} \$ 50,00$ por hora de fornecimento). Tal alternativa requer menos informações e tem sido utilizada em pequenos projetos de irrigação com poucos usuários por dia (SMALL; CARRUTHERS, 1991; BANDARAGODA, 1998).

Métodos de cobrança não volumétricos cobram indiretamente pela água com base na cobrança por produto, por insumo, por área e por valorização da área irrigada. $\mathrm{Na}$ cobrança por produto, aplica-se uma taxa por unidade de cada produto produzido por cada usuário da água. Nos casos em que a produção total é facilmente observada, este método economiza em custos de transação. Similarmente, o método de cobrança por insumo cobra pela água indiretamente, via aplicação de uma taxa 
sobre outros insumos de produção (e.g., $\mathrm{R} \$ 2,00$ por quilograma de fertilizante comprado). Os métodos de cobrança por produto e por insumo eliminam os custos com a coleta de informações sobre o efetivo uso da água, mas criam custos com a coleta de informações sobre a produção e a utilização de insumos pelos produtores. A cobrança por área é fácil de ser implementada e administrada, principalmente em locais com fluxo contínuo de água, sendo aplicado em mais do que $60 \%$ dos casos de cobrança pelo uso da água no mundo (JOHANSSON, 2000). Por este método, a cobrança se dá com base no total de área irrigada, sendo o preço por unidade de área estabelecido com base na cultura explorada, na extensão total da área irrigada, no método de irrigação utilizado e na época do ano. Já a cobrança por valorização da área irrigada visa capturar o valor implícito da água para irrigação via cobrança de uma taxa por unidade de área, segundo o aumento no valor da terra. Assim, a cobrança por valorização da área estabelece uma contribuição a ser realizada pelos agricultores que tiveram suas terras valorizadas após a implementação de projetos de irrigação pelo governo.

O último método de cobrança pelo uso da água em projetos de irrigação se fundamenta na possibilidade de se criar mercados que se incumbiriam de alocar a água de acordo com o seu valor real, promovendo ganhos de eficiência e conservação (HEARNE; EASTER, 1995). Os mercados geram mecanismo mais flexível para a alocação de água do que os meios em que a administração é centralizada (MARINO; KEMPER, 1999). Contudo, há várias características associadas à produção e ao fornecimento de água que tornam difícil a criação de mercados competitivos para a água, por exemplo, a presença de informação assimétrica e externalidades e a existência de elevados custos fixos no fornecimento de água que geram custo médio decrescente - e.g., problema do monopólio natural. Mesmo assim, mercados para a água nascem informalmente quando ocorre escassez de recursos ou quando os governos falham em responder rapidamente a mudanças na demanda por água (THOBANI, 1998). Normalmente, tais mercados informais são constituídos por agricultores que vendem sobras de água em um período de tempo (e.g., época de plantio) para propriedades ou cidades vizinhas. No caso do Brasil, a legislação em vigor outorga o uso e não a propriedade da água aos seus usuários. Assim, a legislação brasileira considera ilegal a transferência ou venda da água para terceiros, o que torna ainda mais difícil a criação de mercados para água.

O presente artigo concentra-se no método volumétrico de cobrança pela água, admitindo-se que o preço a ser cobrado por $\mathrm{m}^{3}$ de água poderia ser o preço sombra médio, estimado para a água em um esquema de preço único ou, alternativamente, o preço sombra da água estimado por produtor em um esquema de discriminação perfeita de preços. 


\section{Precificação da Água para Irrigação}

A precificação da água parte da premissa de que o preço funciona como um sinal que indica aos seus usuários o seu valor e leva-os a racionalizar o seu uso. Contudo, ainda não é claro como deve ser conduzida a precificação da água (TSUR, 2005). Como ponto de partida, a fonte natural do preço de um recurso é o seu mercado. Contudo, mercados para água ou não existem ou não funcionam apropriadamente, fato que cria a necessidade de se empregar métodos de precificação.

Existem métodos de precificação da água fundamentados na estimação de curvas de demanda; na estimação de funções de produção e subsequente simulação das perdas em produção devido à utilização de uma menor quantidade de água; na estimação dos custos de provisão de água, se uma fonte preexistente não estivesse disponível, e no uso de métodos de avaliação contingente (BRISCOE, 1996; CARRAMASCHI et al., 2000). As estimativas obtidas com tais métodos podem não ser muito confiáveis, uma vez que o valor da água varia muito dependendo do seu uso, da renda e características do usuário, e de fatores que afetam a disponibilidade e confiabilidade do suprimento de água. Mesmo assim, tais estimativas geram direcionamentos para propostas de políticas públicas.

As políticas de gerenciamento do uso da água, atualmente adotadas, dão prioridade aos custos de suprimento e ao consumo global de água nos projetos. Como a orientação é voltada para o lado da oferta, normalmente não são utilizados modelos de demanda por água capazes de captar os anseios dos usuários, nem seus desperdícios. Estudos sobre a demanda de água gerariam informações sobre as quantidades e preços que os produtores estariam dispostos a pagar pela água, preços esses que poderiam ser bem diferentes daqueles que possibilitariam a recuperação dos custos de suprimento (PINHEIRO; SHIROTA, 2000).

Cabe então destacar que o método de estimação da função insumo distância paramétrica apresenta um enfoque de demanda por água e utiliza dados em nível de produtor, permitindo assim captar desperdícios e contemplar características peculiares à tecnologia utilizada e aos agricultores. 


\section{Metodologia}

\subsection{Modelo Conceitual}

Considere que cada produtor, indexado por $i=1, \ldots, I$, pode produzir até $M$ produtos, utilizando $N$ insumos. A produção do $m$-ésimo produto, $y_{m}$, requer a utilização do vetor insumo, $\mathbf{x}_{\mathrm{m}}=\left(\begin{array}{llll}x_{m 1} & x_{m 2} & \ldots & x_{m n}\end{array}\right)^{\prime}$. Para simplificar a exposição, considere que cada produto é produzido segundo a função de produção $f_{m}\left(\mathbf{x}_{m}\right)$, ou seja, admita que a tecnologia é aditivamente separável e a mesma para todo produtor. Os insumos estão disponíveis em quantidades limitadas por produtor de acordo com o vetor $\overline{\mathbf{x}}^{i}=\left(\bar{x}_{1}^{i} \bar{x}_{2}^{i} \ldots \bar{x}_{n}^{i}\right)$, onde $\bar{x}_{n}^{i}$ denota a quantidade física disponível do $n$-ésimo insumo para o $i$-ésimo produtor. Os produtores são tomadores de preços e determinam a quantidade a demandar de cada insumo, segundo a solução do problema de minimização do custo total de produção (1).

$$
C_{i}\left(\overline{\mathbf{x}}^{i}, \mathbf{p}, \mathbf{y}^{i}\right)=\min _{\left\{\mathbf{x}_{1}^{i}, \ldots, \mathbf{x}_{M}^{i}\right\}} \sum_{m=1}^{M} \mathbf{p} \mathbf{x}_{m}^{i}
$$

sujeito a:

$$
\begin{aligned}
& f_{m}\left(\mathbf{x}_{m}^{i}\right) \geq y_{m}^{i} \text { para } m=1, \ldots, M \\
& \overline{\mathbf{x}}^{i} \geq \sum_{m=1}^{M} \mathbf{x}_{m}^{i}
\end{aligned}
$$

onde $C_{i}\left(\overline{\mathbf{x}}^{i}, \mathbf{p}, \mathbf{y}^{i}\right)$ é a função custo de produção do produtor $i, \mathbf{y}^{i}=\left(y_{1}^{i} \mathbf{y}_{2}^{i} \ldots y_{M}^{i}\right)^{\prime}$ é o vetor produção para o produtor $i, \mathbf{x}^{i}=\left(x_{1}^{i} x_{2}^{i} \ldots x_{N}^{i}\right)^{\prime}$ é o vetor insumo para o produtor $i$ e $\mathbf{p} \in R_{+}^{N}$ é o vetor preços dos insumos.

Observe que o problema (1) possui $M$ restrições, devido a (lb) e mais $N$ restrições, devido a (lc). De especial interesse são as restrições (lc) e os seus multiplicadores de Lagrange. $\mathrm{O}$ valor do multiplicador de Lagrange de uma restrição na solução do problema (1) informa o quanto o custo total poderia ser reduzido, caso fosse disponibilizada uma unidade adicional desse insumo. Esse valor é convencionalmente chamado de preço sombra do insumo e indica a disposição a pagar do produtor $i$ por uma unidade adicional do mesmo. Se fosse possível especificar o problema (1) para cada produtor, poder-se-ia calcular a disposição a pagar por unidades adicionais de cada insumo por produtor. Contudo, a implementação de tal alternativa reque- 
reria o conhecimento das $M$ funções de produção e do vetor de restrições físicas dos insumos, $\overline{\mathbf{x}}^{i}$, para cada produtor.

O problema (1) formaliza a hipótese de que restrições ativas sobre as quantidades disponíveis dos insumos explicam diferenças entre o preço de mercado e o preço sombra de um insumo para um produtor. Adicionalmente, existem outras hipóteses plausíveis que buscam explicar tais diferenças. Por exemplo, Baños-Pino, FernãndezBlanco e Rodríguez-Álvarez (2002) demostram que, se o produtor visa maximizar a sua utilidade, que é uma função do lucro e da quantidade utilizada de cada insumo, os preços sombra dos insumos poderiam diferir dos seus preços de mercado. Nessa mesma linha de raciocínio, Picazo-Tadeo e Reig-Martinez (2005) propõem que a regra segundo a qual o agricultor determina a quantidade ótima de mão de obra familiar a utilizar, tal que a produtividade marginal da mão de obra se iguale ao custo de oportunidade da mesma, pode não ser válida. A razão para tanto é que o agricultor pode preferir ter sua família trabalhando no próprio negócio do que fora dele; por exemplo, porque reduz custos com a necessidade de monitoramento dos trabalhadores ou mesmo porque a mão de obra familiar é tecnicamente melhor. Por tudo isso, o preço sombra da mão de obra familiar pode ser inferior ao preço da mão de obra no mercado de trabalho.

No caso específico do insumo água para irrigação, pode-se admitir diferenças entre o preço da água e o seu preço sombra por duas razões: se o produtor realmente se depara com uma restrição na quantidade disponível desse insumo, nos moldes do problema (1), ou se, nos moldes dos trabalhos de Baños-Pino, Fernãndez-Blanco e Rodríguez-Álvarez (2002), o agricultor possui clara preferência pela conservação da água, o que torna o preço sombra da água maior do que o valor cobrado que pode ser inclusive zero.

O método para precificar a água para irrigação, proposto no presente trabalho, permite o cálculo dos preços sombra dos insumos de produção por produtor, tomando a composição de insumos e produtos observada, sem a necessidade de se conhecer: os limites físicos das quantidades disponíveis por insumo e produtor, as funções de produção e as outras potenciais razões para que o preço de mercado de um insumo seja diferente do seu preço sombra.

\subsection{Função Insumo Distância, Demanda Condicionada por Fatores e Preços Sombra}

Considere que o vetor insumo $\mathbf{x} \equiv \sum_{m=1}^{M} \mathbf{x}_{m}=\left(x_{1} x_{2} \ldots x_{N}\right)^{\prime}$ é empregado na produção de um vetor produto y, segundo uma tecnologia $T$, caracterizada por pares de vetores $(x, y)$, tal que $x$ pode produzir $y$. Admita que essa tecnologia pode ser completamente 
definida por seu conjunto requerimento dos fatores, $X(\mathbf{y})=\left\{\mathbf{x} \in \mathfrak{R}_{+}^{N}:(\mathbf{x}, \mathbf{y}) \in T\right\}$. Com base nisso, pode-se definir a função insumo distância, $D_{I}: \mathfrak{R}_{+}^{M} \times \mathfrak{R}_{+}^{N} \rightarrow \mathfrak{R}_{+} \cup\{+\infty\}$, de forma mais conveniente em termos do conjunto requerimento dos fatores como em (2):

$$
D_{I}(\mathbf{x}, \mathbf{y})=\sup _{\theta}\{\theta:(\mathbf{x} / \theta) \in X(\mathbf{y})\} \text { para todo } \mathbf{y} \in R_{+}^{M}
$$

em que $D_{I}(\mathbf{x}, \mathbf{y})$ é a função insumo distância.

O operador supremum (sup) é empregado em (2) de modo a contemplar a possibilidade de se produzir nada com quantidades positivas de insumos, quando $D_{I}(\mathbf{x}, \mathbf{0})=+\infty$. Isso porque se nada é necessário para se produzir nada, então qualquer vetor insumo $\mathbf{x}$ pode ser reduzido ao vetor nulo via contração infinita (HAILU; VEEMAN, 2000). Ademais, sob a hipótese de no free lunch, segundo a qual não se consegue produzir algo a partir de nada, $D_{I}(\mathbf{0}, \mathbf{y})=0$.

A Figura 1 ilustra a função insumo distância para o caso em que a tecnologia utiliza apenas dois fatores de produção, ou seja, $\mathbf{x}=\left(x_{1} x_{2}\right)^{\prime}$ é empregado na produção de $\mathbf{y} \in R_{+}^{M}$. O vetor $y^{0}$ determina o conjunto requerimento dos fatores, $X\left(\mathbf{y}^{0}\right)$, e o vetor insumo, $\mathbf{x}^{0}$, é observado como sendo capaz de produzir $\boldsymbol{y}^{0}$. $\mathrm{O}$ valor da função insumo distância, $D_{I}\left(\mathbf{x}^{0}, \mathbf{y}^{0}\right)$, é tal a posicionar $\mathbf{x}^{0} / D_{I}\left(\mathbf{x}^{0}, \mathbf{y}^{0}\right)$ exatamente sobre a fronteira inferior do conjunto requerimento dos fatores $X\left(\mathbf{y}^{0}\right)$, que é a isoquanta para $\boldsymbol{y}^{0}$ e é definida como o conjunto $Q\left(\mathbf{y}^{0}\right) \equiv\left\{\mathbf{x} \in R_{+}^{N}: \mathbf{x} \in X\left(\mathbf{y}^{0}\right), \mathbf{x} \notin X\left(\mathbf{y}^{0}\right)\right.$ para $\mathbf{y}>\mathbf{y}^{0}$ com $\mathbf{y} \geq 0\}$. Observe que todo vetor $\mathbf{x}$ que pertence ao conjunto isoquanta de $\mathbf{y}$ implica que $D_{I}(\mathbf{x}, \mathbf{y})=1$ e vice-versa. 


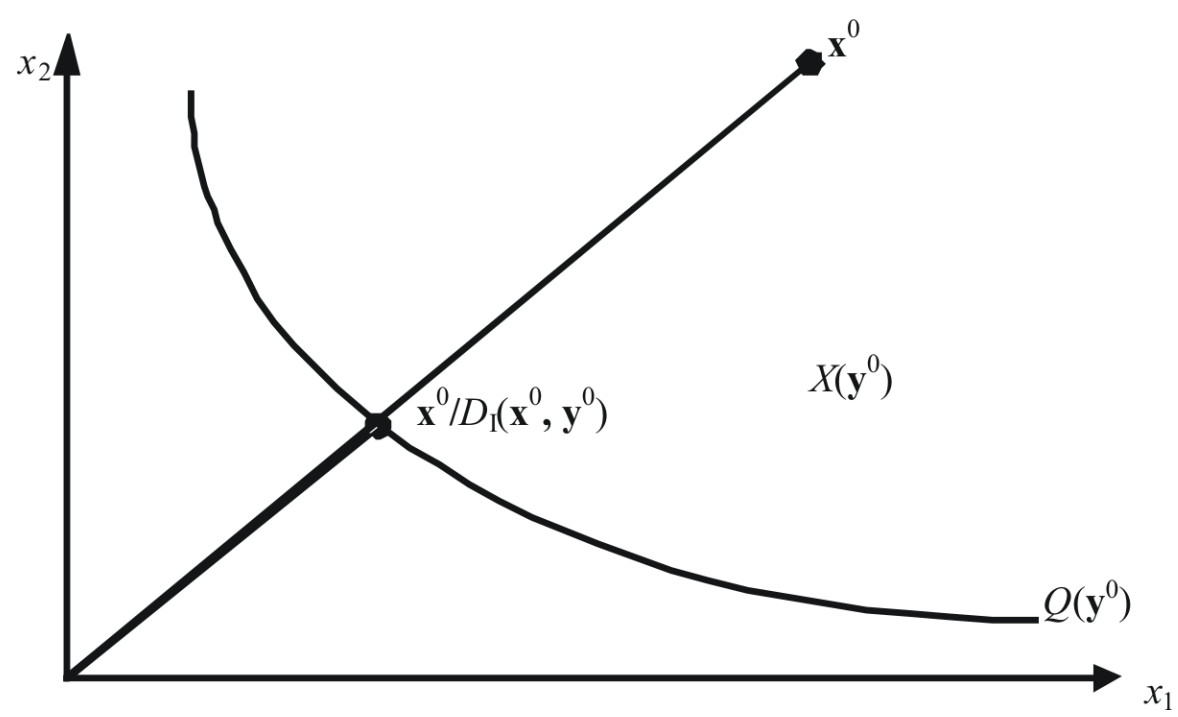

Figura 1 - Representação Gráfica de uma Função Insumo Distância

Sob a hipótese de que os produtores tomam preços, a função custo de produção será a função valor do problema de minimização dos gastos condicionados ao nível de produção, y, ou seja:

$$
C(\mathbf{y}, \mathbf{w})=\min _{\mathbf{x}}(\mathbf{w} \mathbf{x}: \mathbf{x} \in X(\mathbf{y})\} \operatorname{com} \mathbf{y} \in \operatorname{Dom} X \text { e } \mathbf{w} \in \mathfrak{R}_{++}^{N}
$$

em que $\mathbf{w}$ é o vetor preços sombra dos insumos. A condição $\mathbf{y} \in \operatorname{Dom} X$ requer que todo vetor $\mathbf{y}$ pertença ao domínio do conjunto requerimentos dos fatores, $X$, ou seja, y deve ser tecnicamente factível.

Ao se permitir que o preço do insumo seja diferente do preço de mercado, dá-se maior flexibilidade à formulação do problema. Por exemplo, a pressuposição de minimização dos custos pode se sustentar mesmo para quando produtores que produzem o mesmo vetor $\mathbf{y}$, com a mesma tecnologia, estejam utilizando diferentes vetores insumos. Nesses casos, o que faz com que as quantidades dos insumos sejam diferentes por produtor são os preços sombra dos insumos, que são diferentes para cada um deles.

Färe e Primont (1995, p. 21-22) demonstram que o conjunto requerimento dos insumos pode ser completamente caracterizado pela função insumo distância, desde que a hipótese de livre descarte fraco $^{1}$ dos insumos seja atendida (i.e., se $\mathbf{x}$ pode

1 Note que livre descarte fraco é condição suficiente, mas não necessária para livre descarte forte, uma vez que livre descarte forte ocorre se $\mathbf{x}^{\prime} \geq \mathbf{x} \in X(\mathbf{y})$, então $\mathbf{x}^{\prime} \in X(\mathbf{y})$. 
produzir $\mathbf{y}$, então um novo vetor insumo resultante do aumento proporcional em $\mathbf{x}$, por exemplo, $t \mathbf{x}$ com $t \geq 1$, também pode produzir y). Como a função insumo distância admite, por construção, livre descarte fraco dos insumos, então $X(\mathbf{y})=\left\{\mathbf{x}: D_{I}(\mathbf{x}, \mathbf{y}) \geq 1\right\}$, com $\mathbf{y} \in \mathfrak{R}_{+}^{M}$, ou seja, $\mathbf{x} \in X(\mathbf{y})$ se somente se $D_{I}(\mathbf{x}, \mathbf{y}) \geq 1$. Aplicando esse resultado à definição em (3), é possível redefinir a função custo como em (4a).

Färe e Primont (1995, p. 47) estabelecem e demostram a dualidade entre a função insumo distância e a função custo, como estabelecido em (4).

$$
C(\mathbf{y}, \mathbf{w})=\min _{\mathbf{x}}\left\{\mathbf{w} \mathbf{x}: D_{I}(\mathbf{y}, \mathbf{x}) \geq 1\right\}, \operatorname{com} \mathbf{w} \in R_{++}^{N}
$$

se somente se

$$
D_{I}(\mathbf{y}, \mathbf{x})=\inf _{\mathbf{w}^{s}}\left\{\mathbf{w}^{s} \mathbf{x}: C\left(\mathbf{y}, \mathbf{w}^{s}\right) \geq 1\right\}, \operatorname{com} \mathbf{x} \in R_{+}^{N}
$$

onde $\mathbf{w}^{\mathrm{S}}$ é o vetor preços sombra normalizados pelo custo total de produção, ou seja, $\mathbf{w}^{s} \equiv \mathbf{w} / C(\mathbf{y}, \mathbf{w})($ FÄRE; PRIMONT, 1995, p. 48).

A solução do problema em (4a) é o vetor de demandas condicionadas por insumos, $\mathbf{x}(\mathbf{y}, \mathbf{w})$, ao passo que a solução do dual em (4b) é o vetor de demandas condicionadas inversas por insumos, $\mathbf{w}^{s}(\mathbf{y}, \mathbf{x})$. Sabe-se que a demanda condicionada por dado insumo é não crescente no preço desse insumo, propriedade essa que passa automaticamente para a demanda inversa. Dessa forma, o preço sombra de um insumo é menor ou igual ao montante que o produtor estaria disposto a pagar por cada uma das outras unidades já adquiridas desse insumo. Assim, ao se estabelecer o preço de um insumo igual ao seu preço sombra, não causaria qualquer alteração na decisão do produtor acerca da composição insumo produto a utilizar.

Para que seja possível fazer uso da relação de dualidade em (4) é necessário que as funções custo e a função insumo distância sejam diferenciáveis. No presente artigo, esse requerimento é atendido especificando-se a função logaritmo insumo distância segundo a forma funcional translog (vide equação 8).

Admitindo-se que $D_{I}($.$) é diferenciável, pode-se aplicar o teorema do envelope ao pro-$ blema de minimização em (4b), obtendo como resultado: $\nabla_{\mathbf{x}} D_{I}(\mathbf{y}, \mathbf{x})=\mathbf{w}^{s}(\mathbf{x}, \mathbf{y})$. Assim, o vetor de preços sombra absolutos, w, pode ser obtido aplicando $\mathbf{w}=C(\mathbf{y}, \mathbf{w}) \nabla_{\mathbf{x}} D_{I}(\mathbf{y}, \mathbf{x}) .^{2} \mathrm{O}$ problema é que $C(\mathbf{y}, \mathbf{w})$ é função dos preços sombra

2 Vide detalhes em Färe e Primont (1995, p. 55-56). 
absolutos a serem estimados, o que faz com que $C(\mathbf{y}, \mathbf{w})$ seja, de fato, desconhecida. Para superar essa dificuldade, utilizam-se os preços sombra relativos dos insumos, tal que: $\frac{w_{n}}{w_{n^{\prime}}}=\frac{C(\mathbf{y}, \mathbf{w}) \partial D_{I}(\mathbf{y}, \mathbf{x}) / \partial x_{n}}{C(\mathbf{y}, \mathbf{w}) \partial D_{I}(\mathbf{y}, \mathbf{x}) / \partial x_{n^{\prime}}}$ que, após cancelar o termo $C(\mathbf{y}, \mathbf{w})$ no numerador e no denominador da relação, resulta em:

$$
\frac{w_{n}}{w_{n^{\prime}}}=\frac{\partial D_{I}(\mathbf{y}, \mathbf{x}) / \partial x_{n}}{\partial D_{I}(\mathbf{y}, \mathbf{x}) / \partial x_{n^{\prime}}}
$$

onde $w_{n}$ e $w_{n^{\prime}}$ denotam os preços sombra absolutos dos insumos $n$ e $n^{\prime}$.

Em seguida, é necessário assumir que o preço sombra absoluto de um dos insumos, por exemplo, o preço sombra do insumo $n$, é o seu próprio preço de mercado, o que torna possível recuperar os preços sombra absolutos ou, simplesmente, preços sombra dos demais insumos segundo a equação (6):

$$
w_{n^{\prime}}=w_{n} \frac{\partial D_{I}(\mathbf{y}, \mathbf{x}) / \partial x_{n^{\prime}}}{\partial D_{I}(\mathbf{y}, \mathbf{x}) / \partial x_{n}} \forall n^{\prime} \neq n
$$

De (6) é possível notar que o preço sombra, $w_{n^{\prime}}$, informará o quanto o produtor estaria disposto a pagar por uma unidade adicional do insumo $n^{\prime}$, segundo a taxa marginal de substituição técnica entre os insumos $n$ e $n^{\prime}$ valorada aos preços do insumo $n$. Assim, a utilização de uma unidade adicional do insumo $n^{\prime}$ possibilitaria ao produtor deixar de gastar $w_{n} \frac{\partial D_{I}(\mathbf{y}, \mathbf{x}) / \partial x_{n^{\prime}}}{\partial D_{I}(\mathbf{y}, \mathbf{x}) / \partial x_{n}}$ unidades monetárias com o insumo $n$ e, mesmo assim, continuar produzindo o vetor produto y. Ou seja, o lado direito de (6) gera o montante potencialmente economizado em unidades monetárias com a substituição do insumo $n$ pelo insumo $n^{\prime}$.

Färe e Primont (1995, p. 40) demonstram que retornos de escala locais podem ser obtidos a partir da função insumo distância com o cálculo da elasticidade de escala via aplicação de (7):

$$
\varepsilon_{I}(\mathbf{y}, \mathbf{x})=\frac{-1}{\nabla_{\mathbf{y}} D_{I}(\mathbf{y}, \mathbf{x}) \mathbf{y}}
$$

onde se diz que a tecnologia exibe localmente retornos crescentes, constantes ou decrescentes se $\varepsilon_{I}(\mathbf{y}, \mathbf{x})$ é maior, igual ou menor do que um (VARIAN, 1992, p. 17). 


\subsection{Especificação e Estimação da Função Insumo Distância}

Dadas as características do método, a função insumo distância deve ser diferenciável em todo o seu domínio. Uma função que atende a esse pré-requisito e, adicionalmente, é flexível para permitir grande variedade de substituição entre insumos e padrões de transformação é a função translog (CHRISTENSE et al., 1973).

A parametrização da função logaritmo insumo distância, com a utilização da função translog, tem sido adotada em trabalhos prévios em diferentes contextos. Por exemplo, Färe et al. (1993), Coggins e Swinton (1996) e Hailu e Veeman (2000) utilizaram esse procedimento no cálculo de preços sombra para produtos indesejáveis do ponto de vista ambiental. Já Picazo-Tadeo e Reig-Martínez (2005) empregaram esse mesmo procedimento no cálculo do preço sombra da mão de obra familiar em propriedades citrícolas da Espanha, no intuito de investigar a eficiência da agricultura familiar e especular sobre o valor da mão de obra familiar vis-à-vis à mão de obra contratada.

A função logaritmo insumo distância translog para o $i$-ésimo produtor é especificada como (8).

$$
\begin{aligned}
\ln D_{I}\left(\mathbf{x}^{i}, \mathbf{y}^{i}\right)= & \alpha_{0}+\sum_{m=1}^{M} \alpha_{m} \ln y_{m}^{i}+\frac{1}{2} \sum_{m=1}^{M} \sum_{m^{\prime}=1}^{M} \alpha_{m m^{\prime}} \ln y_{m}^{i} \ln y_{m^{\prime}}^{i}+\sum_{n=1}^{N} \beta_{n} \ln x_{n}^{i}+ \\
& +\frac{1}{2} \sum_{n=1}^{N} \sum_{n^{\prime}=1}^{N} \beta_{n n^{\prime}} \ln x_{n}^{i} \ln x_{n^{\prime}}^{i}+\sum_{n=1}^{N} \sum_{m=1}^{M} \delta_{n m} \ln x_{n}^{i} \ln y_{m}^{i}
\end{aligned}
$$

Os parâmetros da função logaritmo insumo distância (8) são estimados, no contexto do problema (9), por um procedimento de programação linear conhecido como goal programming. Esse procedimento é adotado em virtude da sua flexibilidade em permitir a imposição de restrições ao problema, tendo sido pioneiramente desenvolvido e aplicado por Aigner e Chu (1968) em um contexto de estimação de fronteiras de produção. Tal procedimento estima os parâmetros da função logaritmo insumo distância translog, de modo a minimizar a soma dos desvios dos valores logaritmizados da função insumo distância com relação ao $\ln (1)$, que é zero. Procedendo dessa maneira, o procedimento goal programming calcula os parâmetros da equação (8), de modo a minimizar a ineficiência técnica agregada dos produtores amostrados, conforme formalizado pela função objetivo (9a). Quanto mais próximo de 1 é a função insumo distância ou, equivalentemente, mais próximo de zero é o logaritmo da função insumo distância, mais eficiente é o produtor em questão. Além disso, o procedimento é capaz de garantir que a função insumo distância seja 
não decrescente e linear homogênea em x, e não crescente em y (KUMBHAKAR; LOVELL, 2000, p. 30).

$$
\min _{\{\alpha, \beta, \delta\}} \sum_{i=1}^{I}\left[\ln D_{I}\left(\mathbf{x}^{i}, \mathbf{y}^{i}\right)-\ln 1\right]
$$

sujeito a:

$$
\begin{array}{lc}
\ln D_{I}\left(\mathbf{x}^{i}, \mathbf{y}^{i}\right) \geq 0 & \text { para } i=1, \ldots, I \\
\frac{\partial \ln D_{I}\left(\mathbf{x}^{i}, \mathbf{y}^{i}\right)}{\partial \ln x_{n, i}} \geq 0 & \text { para todo } i=1, \ldots, I, \text { e } n=1,2, \ldots, N \\
\frac{\partial \ln D_{I}\left(\mathbf{x}^{i}, \mathbf{y}^{i}\right)}{\partial \ln y_{m, i}} \leq 0 & \text { para todo } i=1, \ldots, I, \text { e } m=1,2, \ldots, M \\
\sum_{n=1}^{N} \beta_{n}=1 & \\
\sum_{n=1}^{N} \beta_{n n^{\prime}}=0 & \text { para } n^{\prime}=1, \ldots, N \\
\sum_{n=1}^{N} \delta_{n m}=0 & \text { para } m=1, \ldots, M \\
\alpha_{m m^{\prime}}=\alpha_{m^{\prime} m} & \text { para } m, m^{\prime}=1, \ldots, M \\
\beta_{n n^{\prime}}=\beta_{n^{\prime} n} & \text { para } n, n^{\prime}=1, \ldots, N
\end{array}
$$

onde as restrições (9b) impõem que o logaritmo neperiano da função insumo distância seja maior ou igual a $\ln l=0$, o que é equivalente a se impor que a função insumo distância seja maior ou igual a 1 . As restrições (9b) visam garantir que o vetor $\mathbf{x}^{i}$ seja capaz de produzir $\mathbf{y}^{i}$, o que assegura condições suficientes para a validade da relação de dualidade em (4). As restrições (9c) garantem que a função insumo distância seja não decrescente na quantidade dos insumos para cada produtor $i$. As restrições (9d) garantem que a função insumo distância seja não crescente no nível dos produtos para cada produtor $i$. As restrições (9el, 9e2 e 9e3) garantem que a função insumo distância seja homogênea de grau um na quantidade dos insumos. As restrições ( $9 \mathrm{fl}$ e 9f2) garantem simetria da matiz de substituição, de modo a respeitar o teorema 
de Young. As propriedades da função insumo distância são apresentadas e demonstradas em Färe e Primont (1995) e em Kumbhakar e Lovell (2000, p. 30).

Um programa com o software Matlab da MathWorks Incorporation foi desenvolvido de modo a tornar operacional a formalização e resolução do problema de programação linear (9). Para tanto, foi utilizado o toolbox de otimização do Matlab, especificamente, a sua rotina linprog.

Dadas as características da amostra utilizada no presente trabalho, constituída por 41 produtores, um produto e cinco insumos, o problema (9) tem ao todo 304 restrições, quando aplicado à amostra completa de colonos. Em particular, há 41 restrições relativas a (9b), 246 restrições relativas às restrições de monotonicidade (205 restrições devido aos insumos e 41 devido ao produto), sete restrições envolvendo a homogeneidade linear nos insumos da função insumo distância e dez restrições envolvendo a imposição de simetria da função translog.

Pelo teorema do envelope, as demandas (condicionadas) inversas por insumos normalizadas, $\mathbf{w}^{s}(\mathbf{y}, \mathbf{x})$, são a derivada parcial da função insumo distância com relação à quantidade do insumo de interesse. Assim, as elasticidades dos preços sombra com relação às quantidades utilizadas dos insumos, no caso da especificação translog, são calculadas com base nas equações (10) e (11).

$$
\begin{aligned}
& \varepsilon_{n n^{\prime}}=\left[\beta_{n n^{\prime}}+S_{n} S_{n^{\prime}}\right] / S_{n} \text { para todo } n \neq n^{\prime} \\
& \varepsilon_{n n}=\left[\beta_{n n}+S_{n}\left(S_{n}-1\right)\right] / S_{n} \text { para todo } n
\end{aligned}
$$

onde $S_{n}$ é a primeira derivada da função logaritmo insumo distância com relação ao logaritmo neperiano do insumo $n, \ln x_{n}$, isto é, $S_{n}=\partial \ln D_{I}(\mathbf{x}, \mathbf{y}) / \partial \ln x_{n}$.

É possível calcular as elasticidades cruzadas da demanda (condicionada) inversa de cada insumo com relação às quantidades do próprio insumo e dos demais insumos. Para tanto, observe que as elasticidades-preço da demanda condicionada por um fator com relação ao próprio preço e aos preços dos demais insumos são o inverso das elasticidades obtidas com as fórmulas (10) e (11). Dessa forma, as elasticidades obtidas com (10) e (11) são, na verdade, elasticidades indiretas (KUMAR, 2006) uma vez que informam a porcentagem de mudança no preço sombra do fator $n$, se a quantidade do fator $n^{\prime}$ se alterasse. Para se obter as elasticidades diretas, basta calcular o inverso dos valores obtidos com (10) e (11). 


\subsection{Descrição dos Dados e Variáveis}

Os dados utilizados são provenientes da pesquisa "Investimentos Públicos e Privados em Agricultura Irrigada e Seus Determinantes sobre o Emprego e a Renda" da Fundação de Apoio ao Desenvolvimento da Universidade Federal de Pernambuco - FADE (1999) -, que abrangeu observações de colonos, empresas agrícolas e empresas agroindustriais da região do Submédio Vale do São Francisco. No presente trabalho, apenas os dados sobre os colonos dos perímetros da região de Petrolina, $\mathrm{PE}$ e Juazeiro, BA, foram utilizados. A composição da amostra utilizada, em contraste à amostra total da pesquisa da FADE (1999) e ao universo de colonos em 1998, na área de estudo, está apresentada na Tabela 1 .

\section{Tabela 1 - Universo de Colonos, Amostra da Pesquisa e Amostra Final Utilizada para os Polos de Irrigação em 1998}

\begin{tabular}{llrrr}
\hline Perímetro & Município & \multicolumn{1}{c}{$\begin{array}{c}\text { Universo de } \\
\text { colonos }\end{array}$} & \multicolumn{1}{c}{$\begin{array}{c}\text { Amostra da } \\
\text { pesquisa }\end{array}$} & \multicolumn{1}{c}{$\begin{array}{c}\text { Amostra final } \\
\text { utilizada }\end{array}$} \\
\hline Nilo Coelho & Petrolina, PE & $1.437(66,7 \%)$ & $134(60,4 \%)$ & $29(70,7 \%)$ \\
Bebedouro & Petrolina, PE & $129(6 \%)$ & $13(5,9 \%)$ & $2(4,9 \%)$ \\
Curaçá & Juazeiro, BA & $267(12,4 \%)$ & $27(12,2 \%)$ & $2(4,9 \%)$ \\
Maniçoba & Juazeiro, BA & $234(10,9 \%)$ & $24(10,8 \%)$ & $6(14,6 \%)$ \\
Mandacarú & Juazeiro, BA & $53(2,5 \%)$ & $11(5,0 \%)$ & $1(2,4 \%)$ \\
Tourão & Juazeiro, BA & $34(1,5 \%)$ & $13(5,9 \%)$ & $1(2,4 \%)$ \\
\hline Total & & 2.154 & 222 & \multicolumn{1}{c}{41} \\
\hline
\end{tabular}

Nota: Valores em parênteses denotam a participação porcentual do perímetro.

Fonte: Pesquisa "Investimentos Públicos e Privados em Agricultura Irrigada e seus Determinantes sobre o Emprego e a Renda". Fundação de Apoio ao Desenvolvimento da Universidade Federal de Pernambuco - FADE, 1999

Do total de 222 colonos amostrados, foi viável utilizar os registros de apenas 41 deles. Isso porque apenas para esses colonos os registros apresentavam todas as informações necessárias à execução do presente trabalho, principalmente no que tange às informações quanto ao consumo de água no ano. Admite-se que a amostra final utilizada é pequena, mas, como demonstra a Tabela 1, a participação porcentual de cada perímetro na amostra final utilizada segue de perto a distribuição do universo de colonos.

Os dados da amostra final utilizada mostraram que há diferentes culturas e métodos de irrigação empregados pelos colonos. Observou-se ainda que há alta correlação entre o método de irrigação empregado e os tipos de culturas cultivadas. No perímetro Nilo Coelho em Petrolina, PE, se produz em ordem de frequência: banana, goiaba, coco, manga, acerola e uva, utilizando-se o método de irrigação por aspersão/ microaspersão. Nos demais perímetros, o método de irrigação, preponderantemente, 
é o da inundação por gravidade e os principais produtos produzidos são em ordem de frequência: coco, goiaba, manga, banana e uva. Dessa forma, para se introduzir a heterogeneidade, ${ }^{3}$ quanto ao método de irrigação utilizado e ao conjunto de produtos produzidos sem subdividir excessivamente a pequena amostra de 41 produtores, optou-se por dividir a amostra final utilizada em apenas dois grupos. O Grupo 1 é formado por colonos que utilizam a aspersão/microaspersão e é composto por 30 colonos, sendo que 29 deles são do perímetro Nilo Coelho e um é do perímetro Bebedouro. Já o Grupo 2 é formado pelos produtores que utilizam inundação por gravidade e é composto por 11 colonos, sendo um do perímetro Bebedouro, seis do perímetro Maniçoba, um do perímetro Mandacarú, dois do perímetro Curaçá e um do perímetro Tourão.

As variáveis utilizadas, suas médias e desvios padrão por grupo de colonos estão na Tabela 2: o valor da produção foi utilizado como proxy da quantidade produzida pelo colono; o gasto com insumos diversos em $\mathrm{R} \$$ corresponde ao gasto com sementes e mudas, adubos, defensivos, herbicida e energia por colono no ano agrícola de 1998; o volume de água está $\mathrm{em}^{3}$ por área total irrigada na propriedade, no ano de 1998; o capital corresponde ao valor presente em $\mathrm{R} \$$ da terra, benfeitorias e maquinaria, descontada a depreciação quando pertinente, e o número de horas de mão de obra considera toda a mão de obra contratada, própria e familiar utilizada por propriedade no ano de 1998.

\section{Tabela 2 - Média e Desvio Padrão dos Dados para as Variáveis para os Dois Grupos} de Colonos na Amostra Final

\begin{tabular}{|c|c|c|c|c|c|}
\hline Variável & Descrição & Unidade & $\begin{array}{c}\text { Colonos utilizando } \\
\text { microaspersão/aspersão } \\
\text { (Grupo 1) }\end{array}$ & $\begin{array}{l}\text { Colonos utilizando } \\
\text { inundação } \\
\text { (Grupo 2) }\end{array}$ & $\begin{array}{l}\text { Amostra } \\
\text { completa }\end{array}$ \\
\hline$y_{1}$ & Valor da produção & $\mathrm{R} \$$ & $\begin{array}{r}119.196,13 \\
(167.410,4)\end{array}$ & $\begin{array}{l}66.527,27 \\
(81.634,2)\end{array}$ & $\begin{array}{r}105.065,46 \\
(150.144,1)\end{array}$ \\
\hline$x_{1}$ & Área total irrigada & ha & $\begin{array}{l}5,36 \\
(1,6)\end{array}$ & $\begin{array}{l}5,48 \\
(1,4)\end{array}$ & $\begin{array}{l}5,40 \\
(1,5)\end{array}$ \\
\hline$x_{2}$ & Gasto com insumos diversos & $\mathrm{R} \$$ & $\begin{array}{l}3.078,00 \\
(2.972,8)\end{array}$ & $\begin{array}{l}2.961,91 \\
(2.222,5)\end{array}$ & $\begin{array}{r}3.046,9 \\
(2.764,9)\end{array}$ \\
\hline$x_{3}$ & Volume de água & $\mathrm{m}^{3}$ & $\begin{array}{r}18.701,45 \\
(34.241,9)\end{array}$ & $\begin{array}{l}286.352,73 \\
(900.214,0)\end{array}$ & $\begin{array}{r}90.510,3 \\
(466.756,0)\end{array}$ \\
\hline$x_{4}$ & Capital & $\mathrm{R} \$$ & $\begin{array}{r}7.807,98 \\
(11.212,4)\end{array}$ & $\begin{array}{l}7.424,82 \\
(5.339,6)\end{array}$ & $\begin{array}{l}7.705,20 \\
(9.914,8)\end{array}$ \\
\hline$x_{5}$ & Mão de obra & horas & $\begin{array}{l}529,77 \\
(432,4)\end{array}$ & $\begin{array}{l}441,64 \\
(531,8)\end{array}$ & $\begin{array}{l}506,10 \\
(455,9)\end{array}$ \\
\hline
\end{tabular}

Nota: Valores em parênteses são desvios padrão.

Fonte: UFPE/FADE (1999).

3 Agradecemos a um parecerista por ter levantado a necessidade de se considerar a heterogeneidade dos produtores em nossas análises. 
Os elevados valores dos desvios padrão na Tabela 2, muitas vezes maiores do que as médias das variáveis, mostram que há grande variabilidade nos dados. Contudo, tal variabilidade é atenuada ao se trabalhar com dois grupos de colonos ao invés de se considerar todos em um mesmo grupo.

\section{Resultados e Discussão}

A Tabela 3 apresenta as estimativas dos parâmetros da função logaritmo insumo distância translog (8), obtidas para a amostra completa e para os grupos 1 e 2 de colonos.

Tabela 3 - Estimativas dos Parâmetros do Insumo Distância Translog Segundo o Método da Programação Matemática

\begin{tabular}{|c|c|c|c|c|c|c|c|c|c|}
\hline \multirow[b]{2}{*}{ Parâmetro } & \multirow[b]{2}{*}{ Variável } & \multicolumn{3}{|c|}{ Estimativas } & \multirow[b]{2}{*}{ Parâmetro } & \multirow[b]{2}{*}{ Variável } & \multicolumn{3}{|c|}{ Estimativas } \\
\hline & & $\begin{array}{l}\text { Amostra } \\
\text { Completa }\end{array}$ & $\begin{array}{c}\text { Grupo } \\
1\end{array}$ & $\begin{array}{c}\text { Grupo } \\
2\end{array}$ & & & $\begin{array}{l}\text { Amostra } \\
\text { Completa }\end{array}$ & $\begin{array}{c}\text { Grupo } \\
1\end{array}$ & $\begin{array}{c}\text { Grupo } \\
2\end{array}$ \\
\hline$a_{0}$ & intercepto & $-1,14$ & $-1,27$ & 1,17 & $b_{32}$ & $\ln x_{3} \ln x_{2}$ & 0,01 & 0,02 & 0,00 \\
\hline$a_{1}$ & $\ln y_{1}$ & 0,04 & 0,05 & $-0,08$ & $b_{33}$ & $\ln ^{2} x_{3}$ & $-0,00$ & 0,00 & $-0,02$ \\
\hline$a_{11}$ & $\ln ^{2} y_{1}$ & $-0,01$ & $-0,01$ & $-0,03$ & $b_{34}$ & $\ln x_{3} \ln x_{4}$ & 0,03 & 0,02 & 0,05 \\
\hline$b_{1}$ & $\ln x_{1}$ & 1,41 & 1,41 & 1,92 & $b_{35}$ & $\ln x_{3} \ln x_{5}$ & 0,03 & 0,03 & $-0,00$ \\
\hline$b_{2}$ & $\ln x_{2}$ & $-0,16$ & $-0,06$ & 0,00 & $b_{41}$ & $\ln x_{4} \ln x_{1}$ & $-0,02$ & $-0,03$ & $-0,09$ \\
\hline$b_{3}$ & $\ln x_{3}$ & $-0,21$ & $-0,20$ & $-0,02$ & $b_{42}$ & $\ln x_{4} \ln x_{2}$ & 0,02 & 0,01 & 0,00 \\
\hline$b_{4}$ & $\ln x_{4}$ & $-0,11$ & $-0,14$ & $-0,83$ & $b_{43}$ & $\ln x_{4} \ln x_{3}$ & 0,03 & 0,02 & 0,05 \\
\hline$b_{5}$ & $\ln x_{5}$ & 0,07 & $-0,02$ & $-0,07$ & $b_{44}$ & $\ln ^{2} x_{4}$ & $-0,02$ & $-0,02$ & 0,04 \\
\hline$b_{11}$ & $\ln ^{2} x_{1}$ & 0,15 & 0,15 & 0,12 & $b_{45}$ & $\ln x_{4} \ln x_{5}$ & $-0,01$ & 0,02 & 0,00 \\
\hline$b_{12}$ & $\ln x_{1} \ln x_{2}$ & $-0,04$ & $-0,03$ & 0,00 & $b_{51}$ & $\ln x_{5} \ln x_{1}$ & $-0,03$ & $-0,03$ & $-0,01$ \\
\hline$b_{13}$ & $\ln x_{1} \ln x_{3}$ & $-0,06$ & $-0,06$ & $-0,03$ & $b_{52}$ & $\ln x_{5} \ln x_{2}$ & 0,01 & $-0,03$ & 0,00 \\
\hline$b_{14}$ & $\ln x_{1} \ln x_{4}$ & $-0,02$ & $-0,03$ & $-0,09$ & $b_{53}$ & $\ln x_{5} \ln x_{3}$ & 0,03 & 0,03 & $-0,00$ \\
\hline$b_{15}$ & $\ln x_{1} \ln x_{5}$ & $-0,03$ & $-0,03$ & $-0,01$ & $b_{54}$ & $\ln x_{5} \ln x_{4}$ & $-0,01$ & 0,02 & 0,00 \\
\hline$b_{21}$ & $\ln x_{2} \ln x_{1}$ & $-0,04$ & $-0,03$ & 0,00 & $b_{55}$ & $\ln ^{2} x_{5}$ & $-0,01$ & 0,02 & 0,01 \\
\hline$b_{22}$ & $\ln ^{2} x_{2}$ & 0,01 & 0,03 & 0,00 & $d_{11}$ & $\ln x_{1} \ln y_{1}$ & 0,01 & 0,00 & $-0,05$ \\
\hline$b_{23}$ & $\ln x_{2} \ln x_{3}$ & 0,01 & 0,02 & 0,00 & $d_{21}$ & $\ln x_{2} \ln y_{1}$ & 0,00 & $-0,01$ & 0,00 \\
\hline$b_{24}$ & $\ln x_{2} \ln x_{4}$ & 0,02 & 0,01 & 0,00 & $d_{31}$ & $\ln x_{3} \ln y_{1}$ & $-0,00$ & $-0,00$ & $-0,01$ \\
\hline$b_{25}$ & $\ln x_{2} \ln x_{5}$ & 0,01 & $-0,03$ & 0,00 & $d_{41}$ & $\ln x_{4} \ln y_{1}$ & 0,00 & 0,01 & 0,05 \\
\hline$b_{31}$ & $\ln x_{3} \ln x_{1}$ & $-0,06$ & $-0,06$ & $-0,03$ & $d_{51}$ & $\ln x_{5} \ln y_{1}$ & $-0,01$ & 0,00 & 0,00 \\
\hline
\end{tabular}

Nota: A amostra completa refere-se aos 41 colonos da amostra final; o Grupo 1 é composto por 30 colonos que utilizam aspersão/microaspersão, e o Grupo 2 é composto pelos 11 colonos que utilizam inundação. 
Observa-se, pela Tabela 3, que as estimativas dos interceptos e coeficientes da função logaritmo insumo distância translog são diferentes entre amostras, o que reforça a necessidade de se considerar a heterogeneidade na análise ${ }^{4}$ e indica a conveniência do procedimento adotado quando comparado ao de Kumar (2006), que utilizou variável dummy de intercepto.

O resultado da resolução do problema (9), que é um problema de programação linear, não permite o cálculo de desvios padrão dos parâmetros, o que impede a realização de testes estatísticos sobre a significância dos mesmos. A função insumo distância poderia ter sido estimada econometricamente se houvesse dados suficientes. Existem apenas 30 observações para o Grupo 1 e 11 para o Grupo 2 e 38 parâmetros a serem estimados para cada grupo, o que inviabiliza a estimação econométrica. Haveria ainda a possibilidade de se restringir a função (8) para a especificação Cobb-Douglas com consequente aumento do número de graus de liberdade, viabilizando a estimação econométrica ao custo de se impor restrições adicionais ao modelo. Por tudo isso, optou-se por aplicar o método discutido no contexto do problema (9) e pioneiramente aplicado por Färe et al. (1993) na estimação de uma função produto distância, para uma amostra de 30 observações de fábricas de papel. Também utilizaram esse método Coggins e Swinton (1996), Hailu e Veeman (2000), Picazo-Tadeo e Reig-Martínez (2005) e Kumar (2006), que aplicou o método em um contexto em que o número de observações, 276, era muito maior do que a amostra utilizada no presente trabalho. Os valores estimados da função insumo distância para cada produtor estão na Tabela 4.

Os dados da Tabela 4 reforçam a importância de se trabalhar com os produtores em grupos separados. Observe que, ao se considerar os 41 produtores juntos (amostra completa), apenas oito deles seriam eficientes, ou seja, 19,51\% dos produtores. Já quando se considera os produtores em grupos separados de acordo com a tecnologia de irrigação, verifica-se que nove produtores são eficientes no Grupo 1 e seis produtores são eficientes no Grupo 2, ou seja, 15 dos 41 produtores $(36,6 \%$ dos produtores) seriam tecnicamente eficientes. Mesmo assim, esse resultado ainda demonstra que muito poderia ser feito no sentido de se aumentar a eficiência técnica dos colonos amostrados, possivelmente via provimento e aprimoramento da assistência técnica aos produtores.

4 Agradecemos a um parecerista por ter sugerido a incorporação da heterogeneidade dos produtores na modelagem via variáveis dummies. Tentamos estimar os modelos com a introdução de variável dummy de intercepto, mas não houve convergência de algoritmo de resolução do problema de programação linear para uma solução. Por isso, optamos por estimar separadamente o modelo para cada grupo de colonos, o que é, inclusive, mais flexível do que o simples uso de variável dummy de intercepto. 
Tabela 4 - Estimativa da Função Insumo Distância por Colono

\begin{tabular}{|c|c|c|c|c|c|c|c|}
\hline \multirow[b]{2}{*}{ Colono } & \multicolumn{3}{|c|}{ Valor da Função Insumo Distância } & \multirow[b]{2}{*}{ Colono } & \multicolumn{3}{|c|}{ Valor da Função Insumo Distância } \\
\hline & $\begin{array}{l}\text { Amostra } \\
\text { Completa }\end{array}$ & Grupo 1 & Grupo 2 & & $\begin{array}{l}\text { Amostra } \\
\text { Completa }\end{array}$ & Grupo 1 & Grupo 2 \\
\hline 185 & 1,28 & & 1,31 & 195 & 1,00 & & 1,00 \\
\hline 183 & 2,66 & & 2,64 & 8 & 2,65 & 1,96 & \\
\hline 133 & 2,29 & & 2,16 & 138 & 1,14 & & 1,38 \\
\hline 171 & 1,00 & & 1,00 & 197 & 1,59 & & 1,51 \\
\hline 182 & 1,02 & & 1,00 & 187 & 2,69 & & 2,68 \\
\hline 202 & 1,02 & & 1,00 & 85 & 1,00 & & 1,00 \\
\hline 222 & 1,00 & 1,00 & & 156 & 1,32 & & 1,42 \\
\hline 47 & 1,49 & 1,26 & & 21 & 1,18 & 1,00 & \\
\hline 100 & 1,66 & & 1,65 & 10 & 1,69 & & 1,63 \\
\hline 91 & 2,30 & & 2,28 & 172 & 1,16 & & 1,00 \\
\hline 189 & 1,39 & & 1,23 & 194 & 1,08 & & 1,03 \\
\hline 140 & 1,20 & & 1,00 & 38 & 1,33 & 1,00 & \\
\hline 191 & 1,27 & & 1,24 & 59 & 1,36 & 1,11 & \\
\hline 144 & 1,00 & & 1,00 & 127 & 1,56 & & 1,56 \\
\hline 78 & 2,31 & 1,00 & & 181 & 1,23 & & 1,24 \\
\hline 31 & 2,24 & 1,00 & & 186 & 1,00 & & 1,04 \\
\hline 184 & 2,37 & & 2,37 & 25 & 1,56 & 1,31 & \\
\hline 175 & 1,00 & & 1,00 & 177 & 1,34 & & 1,31 \\
\hline 193 & 1,54 & & 1,48 & 32 & 1,62 & 1,13 & \\
\hline 54 & 1,00 & 1,00 & & 196 & 1,13 & & 1,05 \\
\hline 157 & 2,62 & & 2,23 & & & & \\
\hline
\end{tabular}

Nota: Valores maiores do que 1 indicam que o colono não foi tecnicamente eficiente.

A média dos valores da função insumo distância, considerando-se os grupos separados, foi de 1,38 , com desvio padrão de 0,52 . O inverso do valor da função insumo distância, $\left(0 \leq 1 / D_{I}(\mathrm{x}, \mathrm{y}) \leq 1\right)$, é a medida de eficiência técnica da unidade produtiva definida por Farrel (1957) e mede a contração radial máxima que um vetor insumo, $\mathbf{x}$, pode sofrer e, ainda assim, produzir $\mathbf{y}$. A média dos valores do inverso da função insumo distância foi 0,725 , indicando que, em média, seria possível manter o atual nível de produção dos 41 colonos, utilizando-se $72,5 \%$ das quantidades de fatores de produção efetivamente empregadas. No caso específico da água e tomando-se as estimativas ponto a ponto, observou-se que $55,62 \%$ da água poderia ter sido economizada, mantendo-se os atuais níveis de produção. Esse dado indica que teria sido possível realizar uma economia de aproximadamente $9.340 \mathrm{~m}^{3}$ de água por hectare por ano, o que seria suficiente para irrigar, por aspersão, 1 ha de fruteiras 
por 1 ano. Os resultados das estimativas dos preços sombra e das elasticidades de escala estão na Tabela 5.

Tabela 5 - Estimativas dos Preços Sombra da Área Irrigada, Insumos Diversos, Água e Mão de Obra e Elasticidades de Escala

\begin{tabular}{|c|c|c|c|c|c|}
\hline & Área Irrigada $(\mathrm{R} \$ / \mathrm{ha})$ & $\begin{array}{l}\text { Insumos } \\
\text { diversos } \\
(\mathrm{R} \$)\end{array}$ & $\begin{array}{l}\text { Água } \\
\left(\mathrm{R} \$ / \mathrm{m}^{3}\right)\end{array}$ & $\begin{array}{c}\text { Mão de obra } \\
\text { (R\$/hora) }\end{array}$ & $\begin{array}{c}\text { Elasticidade de escala, } \\
\qquad \varepsilon_{I}(\mathbf{y}, \mathbf{x}) \\
(\%)\end{array}$ \\
\hline \multicolumn{6}{|c|}{ Grupo 1} \\
\hline Média & $1.925,54$ & 9,87 & 7,30 & 23,93 & 0,06 \\
\hline Desvio padrão & $3.106,48$ & 26,02 & 27,12 & 44,80 & 0,04 \\
\hline \multicolumn{6}{|c|}{ Grupo 2} \\
\hline Média & 553,97 & 2,80 & 3,82 & 114,85 & 0,12 \\
\hline Desvio padrão & 670,94 & 3,35 & 6,48 & 180,44 & 0,08 \\
\hline
\end{tabular}

Os valores na sexta coluna da Tabela 5 mostram que as tecnologias utilizadas pelos dois grupos de colonos exibem retornos de escala localmente decrescentes. Em média, o aumento de $10 \%$ na quantidade utilizada de todos os insumos resultaria no aumento da produção em 0,6\% para o Grupo 1 e em 1,2\% para o Grupo 2. Apesar de se tratar de um resultado local, indica que as tecnologias utilizadas pelos dois grupos de colonos criam deseconomia de escala local, o que justifica a dispersão da área total irrigada em pequenos lotes que apresentam 5,4 ha de área média (vide Tabela 2).

As estimativas dos preços sombra, ${ }^{5}$ na Tabela 5 , foram obtidas segundo a equação (6), admitindo-se que o preço sombra absoluto do capital é igual ao seu preço de mercado, que é $\mathrm{R} \$ 1,00$. Contrastando a média e o desvio padrão dos preços sombra da água, apresentados na quarta coluna da Tabela 5, fica evidente a elevada variabilidade nas estimativas obtidas para os dois grupos de produtores. Note-se que Kumar (2006), utilizando a mesma abordagem, também encontrou elevados erros padrão para os preços sombra da água na indústria na Índia. De qualquer forma, a elevada variabilidade nas estimativas já era esperada, pois os dados utilizados já apresentavam elevada variabilidade (vide Tabela 1). Além disso, parte da variabilidade deve refletir os erros de medida dos dados utilizados nas estimações. No caso específico da água, os colonos eram questionados sobre a quantidade de água que

5 Em tese, os preços sombra devem ser obtidos apenas para unidades tecnicamente eficientes, uma vez que, ao se assumir que as firmas minimizam custos, requer-se que as mesmas sejam técnica e alocativamente eficientes. Contudo, como a função insumo distância é linearmente homogênea nos insumos, não haverá diferenças entre os preços sombra calculados com as quantidade efetivamente utilizadas de insumos ou com sua projeção radial eficiente (PICAZO-TADEO e REIG-MARTÍNEZ, 2005). 
tinham utilizado no ano. Em um contexto em que a inadimplência com relação ao pagamento da água é elevada (SILVA, 1999), é bem provável que os colonos tenham pouco controle sobre a quantidade de água utilizada, pois podem tratar a água como um bem livre. Assume-se que potenciais erros de medida não estão correlacionados com os valores informados, o que justifica a variabilidade e elimina o potencial viés das estimativas devido a erros de medida.

Tomando-se como referência a tarifa média cobrada pela Companhia Pernambucana de Saneamento em 2006, que foi $\mathrm{R} \$ 1,52$ por $\mathrm{m}^{3}$ de água (PNUD, 2008), verificouse que apenas oito colonos no Grupo 1 e três colonos no Grupo 2 estariam dispostos a pagar um valor maior ou igual a esse. Ou seja, apenas $26,8 \%$ dos colonos teriam a disposição de pagar mais do que $\mathrm{R} \$ 1,52$ por $\mathrm{m}^{3}$ de água e permanecer consumindo a mesma quantidade de água. Dessa forma, apesar de o valor médio dos preços sombra da água ser relativamente alto nos dois grupos de colonos, em geral, a água não parece ser muito valiosa para a maioria $(73,2 \%)$ dos produtores amostrados. Tal resultado está em linha com os fatos estilizados, apresentados por Briscoe (1996). Segundo esse autor, o exame dos valores obtidos em diversos estudos visando à estimação do valor da água, permite se chegar a resultados bem consistentes para países em desenvolvimento e desenvolvidos: em geral, (a) o valor da água é baixo quando utilizada na produção de energia ou na agricultura irrigada para produção de grãos para alimentação humana; (b) o valor da água é significantemente maior quando a mesma é para o uso em residências, uso industrial e para a agricultura irrigada, visando à produção de frutas e vegetais, e (c) valores para o uso ambiental ficam algo entre os valores obtidos em (a) e (b).

O preço sombra médio para a mão de obra foi relativamente alto para os dois grupos, especialmente para o Grupo 2, considerando-se que um trabalhador que trabatha 160 horas por mês, por um salário mínimo de $\mathrm{R} \$ 510,00$, adicionado de $46,63 \%$, ${ }^{6}$ ganha $\mathrm{R} \$ 4,67$ por hora trabalhada. Além disso, observou-se que 15 produtores do Grupo 1 e quatro produtores do Grupo 2 (46,34\% dos produtores) estariam dispostos a pagar $\mathrm{R} \$ 4,26$ ou mais por uma hora de mão de obra, indicando haver alguma restrição física quanto à quantidade de mão de obra disponível para esses colonos. Uma interpretação alternativa seria a de que os colonos valorizam muito a mão de obra empregada por se tratar, em grande parte, de mão de obra familiar.

Com relação aos preços sombra dos insumos diversos, observou-se que 17 colonos no Grupo 1 e quatro no Grupo 2, ou seja, 51,2\% dos produtores, estariam dispostos a pagar mais do que $R \$ 1,00$ para poderem gastar $R \$ 1,00$ a mais em insumos

6 Correspondente a $8 \%$ de FGTS, 8,33\% de $13^{\circ}$ salário, 2,5\% de salário-educação, 0,20\% de INCRA, $8,33 \%$ de férias, $2,77 \%$ de abono de férias, $1,5 \%$ de contribuição confederativa e $15 \%$ de seguridade social. 
diversos. Tal resultado indica que os produtores se deparam com restrições financeiras e, assim sendo, estariam dispostos a pagar juros para viabilizar o seu acesso a recursos financeiros adicionais.

Ao se tomar por base o valor de $\mathrm{R} \$ 5.239,00$ por hectare, que é o preço médio de venda da terra em Pernambuco (FGVDADOS, 2008), observou-se, com base nos preços sombra da área irrigada, que apenas três produtores do Grupo 1 e nenhum do Grupo 2, ou seja, 7,3\% dos produtores, estariam dispostos a pagar esse valor ou mais por mais 1 ha de terra irrigada. Assim, não parece que a terra é um recurso escasso ou valioso para os colonos amostrados.

O método empregado ainda permite que se calcule as elasticidades-preço da demanda por fatores, ${ }^{7}$ que são calculadas como o inverso dos valores obtidos com a aplicação das fórmulas (10) e (11) e têm os seus valores médios apresentados nas Tabelas 6 e 7.

Tabela 6 - Estimativas das Elasticidades Próprios-Preços e Preços-Cruzados da Demanda Condicionada por Fatores para os Colonos que Utilizam Aspersão/Microaspersão (Grupo 1)

\begin{tabular}{lccccc}
\hline & Área irrigada & Insumos Diversos & Água & Capital & Mão de obra \\
\hline Área Irrigada & $-0,4057$ & 0,2640 & $-1,9333$ & $-3,6002$ & $-1,8863$ \\
& $(5,139)$ & $(11,330)$ & $(3,723)$ & $(9,876)$ & $(17,021)$ \\
Insumos Diversos & 0,4768 & $-2,0636$ & 3,3476 & 4,4085 & $-2,2007$ \\
& $(11,212)$ & $(1,330)$ & $(1,401)$ & $(2,886)$ & $(9,885)$ \\
Água & $-1,9856$ & 3,6437 & $-1,3570$ & 3,7683 & 3,0080 \\
& $(3,027)$ & $(1,805)$ & $(0,400)$ & $(2,224)$ & $(1,445)$ \\
Capital & $-3,9549$ & 3,9228 & 3,0347 & $-2,9443$ & 3,0278 \\
& $(9,412)$ & $(3,032)$ & $(1,183)$ & $(9,316)$ & $(1,392)$ \\
Mão de obra & $-2,6767$ & $-1,8820$ & 2,5634 & 3,0579 & $-1,6529$ \\
& $(18,475)$ & $(10,077)$ & $(1,130)$ & $(1,687)$ & $(0,914)$ \\
\hline
\end{tabular}

Obs.: Valores entre parênteses são desvios padrão.

7 Agradecemos imensamente a sugestão de um parecerista para que expandíssemos os nossos resultados, calculando elasticidades-preço. 
Tabela 7 - Estimativas das Elasticidades Próprios-Preços e Preços-Cruzados da Demanda Condicionada por Fatores para os Colonos que Utilizam Inundação por Gravidade (Grupo 2)

\begin{tabular}{lccccc}
\hline & Área Irrigada & Insumos Diversos & Água & Capital & Mão de obra \\
\hline Área Irrigada & $-0,5969$ & 3,3011 & $-2,9628$ & $-0,5465$ & 1,2414 \\
& $(2,360)$ & $(4,167)$ & $(9,567)$ & $(3,329)$ & $(3,194)$ \\
Insumos Diversos & 2,0624 & $-0,9620$ & 3,5224 & 2,5870 & 1,6533 \\
\multirow{2}{*}{ Água } & $(3,142)$ & $(0,936)$ & $(5,852)$ & $(4,377)$ & $(2,734)$ \\
& $-0,3814$ & 3,1681 & $-0,6846$ & 0,7383 & 2,5058 \\
Capital & $(2,788)$ & $(3,921)$ & $(0,678)$ & $(0,626)$ & $(12,935)$ \\
& $-0,6033$ & 3,9611 & 1,5247 & $-1,8649$ & 4,8475 \\
Mão de obra & $(4,658)$ & $(4,372)$ & $(1,694)$ & $(1,887)$ & $(6,580)$ \\
& 1,1583 & 2,5345 & 2,9522 & 1,3729 & $-1,0212$ \\
& $(3,874)$ & $(3,707)$ & $(7,199)$ & $(2,168)$ & $(2,050)$ \\
\hline
\end{tabular}

Obs.: Valores entre parênteses são desvios padrão.

Os valores na diagonal principal das Tabelas 6 e 7 são os valores médios das elasticidades próprios-preços dos fatores de produção e são todos negativos como esperado. Tal resultado indica que o aumento no preço do fator de produção reduz a demanda condicionada pelo mesmo e é uma consequência do modelo conceitual, no qual se assume que as firmas minimizam custos. Percebe-se que o capital é o fator de produção com maior elasticidade próprio-preço, indicando que investimentos em capital pelos colonos são muito sensíveis a aumentos na taxa de juros, que é o preço do capital - veja que Kumar (2006) encontrou, para a indústria da Índia, o valor médio de $(-0,589)^{-1}=-1,69$ para a elasticidade-preço do capital. Além disso, o capital é um substituto, com exceção da área irrigada, para todos os outros fatores de produção nos dois grupos de colonos, pois apresentou elasticidades preços-cruzados positivas com relação a todos os outros fatores de produção; o que é razoável, pois melhores benfeitorias e maquinaria podem viabilizar a diminuição na quantidade utilizada dos outros fatores de produção para se manter um determinado nível de produto.

Observa-se também pelas Tabelas 6 e 7 que todo insumo possui pelo menos um substituto (i.e., apresenta elasticidade preço-cruzado positiva), o que é teoricamente esperado. Quando um produtor minimiza custos e reduz a quantidade de um insumo em resposta ao aumento no preço desse insumo, uma tecnologia convexa requererá o aumento na quantidade de, pelo menos, um outro fator de produção para que se mantenha o nível preestabelecido de produção.

Os resultados nas Tabelas 6 e 7 mostram que, para os colonos nos dois grupos, a água é um substituto para insumos diversos, capital e mão de obra e um complemento para área irrigada, apesar de a magnitude dessas elasticidades preços- 
cruzados serem maiores para os colonos utilizando aspersão/microaspersão (Grupo 1). É razoável que a tecnologia permita, até certo ponto, a substituição da água por insumos diversos, capital e mão de obra. Já a complementaridade entre água e área irrigada decorre do fato de que só pode existir área irrigada se houver água para irrigar. O fato é que as elasticidades próprios-preços médias dos dois grupos de colonos demonstram que uma política crível de cobrança pelo uso da água reduziria a demanda por área irrigada e água, e aumentaria a demanda por insumos diversos, capital e mão de obra. Por exemplo, para cada 10\% de aumento no preço da água, haveria uma redução média de 13,57\% e 6,85\% na quantidade demanda de água para os Grupos 1 e 2 de colonos, demonstrando que a cobrança seria um importante instrumento indutor da conservação da água. Note que a magnitude da elasticidade-preço da água é grande nos dois grupos, quando comparada, por exemplo, à estimativa de $-0,5847$, obtida por Féres et al. (2008) para a indústria instalada ao longo da bacia do Paraíba do Sul. Contudo, tal comparação deve ser feita com cautela, visto que Féres et al. (2008) estimaram econometricamente uma função logaritmo custo total translog de curto prazo para a indústria, obtendo as estimativas das elasticidades-preço a partir daí. Porém, as nossas estimativas estão próximas daquela obtida por $\operatorname{Kumar}(2006)$ que foi de $(-0,902)^{-1} \approx 1,11$.

Finalmente, no contexto específico dos colonos amostrados, a inadimplência com relação ao pagamento da água é elevada (SILVA, 1999), o que torna o seu preço de fato zero. Dessa forma, é de se esperar que a simples moralização na cobrança promova enorme impacto em termos de redução no gasto de água sem comprometer os níveis de produção.

\section{Conclusões}

A pressão sobre os recursos hídricos tem criado a necessidade de se reconsiderar os mecanismos até então utilizados na indução do uso eficiente da água, fato esse que é especialmente importante para a agricultura irrigada, uma das atividades que mais consomem água em todo o mundo. A aplicação de mecanismos de cobrança pelo uso requer a precificação da água, que ainda é uma tarefa controversa. Nesse sentido, o presente artigo contribuiu com a literatura ao apresentar um critério objetivo de precificação da água que se fundamenta nas quantidades efetivamente utilizadas de insumos e de produção realizada por produtor. Assim, foi aplicado pela primeira vez a dados coletados no Brasil o método de estimação via programação linear de uma função insumo distância paramétrica na obtenção do preço sombra ou disposição a pagar de cada produtor por $\mathrm{m}^{3}$ de água. Foram utilizados dados coletados com 41 colonos de perímetros irrigados do Submédio São Francisco em Petrolina, PE, e Juazeiro, BA. A heterogeneidade dos produtores foi incorporada à 
análise, estimando-se o modelo separadamente com dados de colonos que utilizam aspersão/microaspersão e que utilizam inundação por gravidade.

As estimativas para a função insumo distância indicaram que, dos 41 produtores na amostra, apenas $15(36,6 \%)$ eram tecnicamente eficientes, resultando na estimativa do índice de Farrell (1957), de eficiência técnica, de 0,725. Assim, seria possível manter-se o nível observado de produção dos 41 colonos amostrados, utilizandose, para tanto, apenas $72,5 \%$ da quantidade empregada de fatores de produção. Especificamente com relação ao fator água, o índice de Farell, tomado ponto a ponto, indicou que $55,62 \%$ da água poderia ter sido economizada, mantendo-se os níveis observados de produção, o que indica que uma política de assistência técnica aos produtores pode gerar efeitos benéficos em temos de racionalização do uso da água.

As médias dos preços sombra estimados da água foram elevadas em valor e apresentaram grande variabilidade, com alguns produtores com disposição a pagar valores relativamente altos por $\mathrm{m}^{3}$ de água. Possivelmente, esse produtores ou experimentam algum tipo de redução no bem-estar com o consumo excessivo de água (i.e., apresentam um viés pró-conservação da água) ou se deparam com uma restrição sobre a quantidade de água disponível. Apesar disso, a água não se mostrou como um fator de produção valioso para a maioria dos produtores, informação essa que deve ser levada em conta na análise de projetos que visem à expansão da capacidade de fornecimento de água para os colonos.

Ainda com relação ao desenho de políticas públicas visando à conservação da água, estimou-se que uma política crível de cobrança poderia fazer com que, para cada $10 \%$ de aumento no preço da água, houvesse uma redução no consumo de água de $13,57 \%$ para os colonos que utilizam aspersão/microaspersão e de 6,85\% para aqueles que utilizam a inundação por gravidade como técnica de irrigação. Tais resultados corroboram a hipótese de que a cobrança pelo uso da água pode funcionar como um sinal de valor que leva à racionalização do seu uso.

Finalmente, os coerentes resultados obtidos com a aplicação do método de estimação por programação linear da função logaritmo insumo distância translog indicam que o mesmo apresenta potencial para ser utilizado na geração de informações importantes para a precificação da água em projetos de irrigação e para o desenho de políticas públicas visando à racionalização do uso da água. 


\section{Referências}

AIGNER, D. J.; CHU, S. F. On estimating the industry production function. The American Economic Review, v. 58, n. 4, p. 826-839, 1968.

ALBINO, J. Abundância e escassez da água: a cobrança pelo uso e um modelo de formação de preços aplicável à bacia hidrográfica GL-1. Dissertação (Mestrado em Economia) - Programa de Pós-Graduação em Economia, Universidade Federal de Pernambuco, Pernambuco. 2003.

BANDARAGODA, D. J. Design and practice of water allocation rules: lessons from Warabandi in Pakistan's Punjab: International Irrigation Management Institute (IIMI), 1998, 34p. (Research Report, 17). Disponível em: <http://www.iwmi. cgiar.org/Publications/IWMI_Research_Reports/PDF/PUB017/REPORT17. $\mathrm{PDF}>$.

BAÑOS-PINO, J.; FERNÁNDEZ-BLANCO, V., RODRÍGUEZ-ÁLVAREZ, A. The allocative efficiency measure by means of a distance function: the case of Spanish public railways. European Journal of Operational Research, v. 137, n. 1, p. 191-205, 2002.

BRISCOE, J. Water as an economic good: The idea and what it means in practice, Cairo: The World Congress of the International Commission on Irrigation and Drainage, September, 1996. Disponível em: <http://www.iph.ufrgs.br/ posgrad/disciplinas/hidp04/Briscoe, $\% 20$ Water\%20as\%20an\%20economic\%20 good.pdf $>$.

CARRAMASCHI, E. C.; CORDEIRO NETO, O. M.; NOGUEIRA, J. M. O preço da água para irrigação: um estudo comparativo de dois métodos de valoração econômica contingente e dose-resposta. Cadernos de Ciência \& Tecnologia, v. 17 , n. 3, p. 59-81, 2000.

CARRERA FERNANDEZ, J. A valorização da água e a cobrança pelo uso: teoria, metodologias e um estudo de caso para a bacia hidrográfica do rio Pirapama em Pernambuco. Ensaios Econômicos, 3. Salvador: UFBA/FCE/CME, 2000.

CHRISTENSEN, L. R.; JORGENSON, D. W.; LAU, L. J. Transcendental logarithmic production frontiers. Review of Economics and Statistics, v. 55, n. 1, p. 28-45, 1973.

COGGINS, J. S.; SWINTON, J. R. The price of pollution: a dual approach to valuing SO2 allowances. Journal of Environmental Economics and Management, v. 30, n. 1, p. 58-72, 1996.

EASTER, K. W.; HEARNE, R. Water markets and decentralized water resources management: international problems and opportunities. Journal of the American Water Resources Association, v. 31, n.1, p. 9-20, 1995.

FÄRE, R.; GROSSKOPF, S.; LOVELL, C. A. K.; YAISAWARNG, S. Derivation of shadow prices for undesirable outputs: a distance function approach. Review of Economics and Statistics, v. 75, n. 2, p. 374-380, 1993. 
FÄRE, R.; PRIMONT, D. Multi-output production and duality: theory and applications. Boston: Kluwer Academic Publishers, 1995.

FARRELL, M. J. The measurement of productive efficiency. Journal of Royal Statistical Society, Series A (General), v. 120, n.3, p. 253-290, 1957.

FÉRES, J.; REYNAUD, A.; THOMAS, A.; SEROA DA MOTTA, R. Competitiveness and effectiveness concerns in water charge implementation: a case study of the Paraíba do Sul River Basin, Brazil. Water Policy, v. 10, n. 6, p. 595-612, 2008.

FGVDADOS. Série de Preços de Vendas de Terras - Lavouras - Brasil. Disponível em: <http://www.fgvdados.fgv.br/bf/dsp_consulta.asp >. Acesso em 31/03/2008.

FOOD AND AGRICULTURE ORGANIZATION (FAO). World agriculture: toward 2015/30 - an FAO perspective. London: Earthscan Publications Ltd, 2003. Disponível em: <http://www.fao.org/docrep/005/y4252e/y4252e00.htm>.

FUNDAÇÃO DE APOIO AO DESENVOLVIMENTO DA UNIVERSIDADE FEDERAL DE PERNAMBUCO (FADE). Investimentos públicos e privados em agricultura irrigada e seus impactos sobre o emprego e a renda nos pólos de Petrolina/Juazeiro e norte de Minas Gerais. Recife, Março, 1999.

HAILU, A.; VEEMAN, T. S. Environmentally sensitive productivity analysis of the Canadian pulp and paper industry, 1959-1994: an input distance function approach. Journal of Environmental Economics and Management, v.40, n. 3, p. 251-74, 2000.

JOHANSSON, R. C. Pricing irrigation water: a literature survey. The World Bank Policy Research Working Paper, n. 2449, p. 1-80, 2000. Disponível em: http:// www-wds.worldbank.org/servlet/WDSContentServer/WDSP/IB/2000/1 1/0 4/000094946_00101705305778/Rendered/PDF/multi_page.pdf

JOHANSSON, R. C.; TSUR, Y.; ROE, T.L.; DOUKKALI, R.M.; DINAR, A. Pricing and allocation of irrigation water: a review of theory and practice. Water Policy, v. 4, n.2, p.173-199, 2002.

KRAEMER, R. A.; PIELEN, B. M.; LEIPPRAND, A. Economic instruments for water management: Extra-regional experience and their applicability in Latin America and the Caribbena. In: KRAEMER, R.A.; CASTRO, Z. G.; SEROA DA MOTA, R.; RUSSELL, C. (Ed.). Economic instruments for water management: Experiences from Europe and implications for Latin America and the Caribbean. Wawhington D.C.: Inter-American Development Bank, Regional Policy Dialogue Studies Series, 2003. p. 3-56 Diponível em: < http://www.ecologic. de/download/projekte/1850-1899/1872/1872-01_final_publication.pdf > .

KUMAR, S. Analysing industrial water demand in India: An input distance function approach. Water Policy, v. 8, n. 1, p. 15-29, 2006.

KUMBHAKAR, S. C.; LOVELL, C. A. K. Stochastic frontier analysis. Cambridge: Cambridge University Press, 2000. 
LANNA, A. E. Estudos para cobrança pelo uso de água bruta no estado do Ceará: simulação tarifária para a bacia do Rio Curu. Fortaleza: COGERH, 1995. (Relatório, 2-A).

MARINO, M.; KEMPER K. E. Institutional frameworks in successful water markets. The World Bank Technical Paper, n. 427, 1999.

PICAZO-TADEO, A. J.; REIJ-MARTÍNEZ, E. Calculating shadow wages for family labour in agriculture: an analysis for Spanish citrus fruit farms. Cahiers d'Economie et Sociologie Rurales, n. 75, p. 5-21, 2005.

PINHEIRO , J. C. V.; SHIROTA, R. Determinação do preço eficiente da água para irrigação no projeto Curu-Paraipaba. Revista Econômica do Nordeste, v. 31, n. 1 p. 36-47, 2000.

PROGRAMA DAS NAÇÕES UNIDAS PARA O DESENVOLVIMENTO (PNUD). Consumo de água diminui em 24 estados. Disponível em: < http://www.pnud. org.br/saneamento/reportagens/index.php?id0l = 1935\&lay=san $>$. Acesso em: 31 mar. 2008.

SEROA DA MOTA, R.; GERES, J. G.; NAUGES, C.; THOMAS, A.; SAADE, A.; SAADE, L. Synthesis of regional experiences: from theoretical to practical issues. In: KRAEMER, R.A.; CASTRO, Z. G.; SEROA DA MOTA, R.; RUSSELL, C. (Ed.). Economic instruments for water management: Experiences from Europe and implications for Latin America and the Caribbean. Wawhington D.C.: Inter-American Development Bank, Regional Policy Dialogue Studies Series, 2003. p. 73-78 Diponível em: < http://www.ecologic.de/download/ projekte/1850-1899/1872/1872-01_final_publication.pdf $>$.

SILVA, J. L. M. A eficiência dos colonos na agricultura irrigada no vale do São Francisco: uma análise comparativa dos modelos de fronteira paramétrica e não paramétrica. Tese (Doutorado em Economia) - Programa de Pós-Graduação em Economia, Universidade Federal de Pernambuco, Pernambuco. 1999.

SMALL, L. E.; CARRUTHERS, I. Farmer financed irrigation: the economics of reform. Cambridge: Cambridge University Press, 1991.

SUASSUNA, J. Recursos hídricos no Nordeste: a necessidade de gerenciamento. Disponível em: < http://www.confea.org.br/publique/media/saofrancisconordeste.doc >. Acesso em: 17 jul. 2008.

THOBANI, M. Meeting water needs in developing countries: resolving issues in establishing tradable water rights, In: EASTER, K. W; ROSEGRANT, M. W.; DINAR, A. (Ed.). Markets for water: potential and performance. Boston: Kluwer Academic Publishers, 1998.

TSUR, Y. Economic aspects of irrigation water pricing. Canadian Water Resources Journal, v. 30, n. 1, p. 31-46, 2005.

TSUR, Y. Water regulation via pricing: the role of implementation costs and asymmetric information. In: DINAR, Ariel (Ed.). The political economy of water pricing reforms. Oxford: Oxford University Press, 2000. p. 105-120. 
TSUR, Y.; ROE, T. ; DOUKKALI, T. ; DINAR, A. (Ed.). Pricing irrigation water: principles and cases from developing countries. Washington D.C.: Rff Press Book, 2003. 319 p.

VARIAN, H. R. Microeconomic analysis. 3a. ed., New York: Norton \& Company, Inc., 1992.

WORLD BANK. World development report 2000/2001: attacking poverty. Washington/New York: World Bank/Oxford University Press, 2001. 